DOCTRIN A

\title{
Justicia y seguridad jurídica en un mundo de ordenanzas municipales desbocadas
}

\author{
Justice and legal security in a world of runaway municipal ordinances
}

\author{
Cristian Román Cordero \\ Universidad de Chile
}

\begin{abstract}
RESUMEN Este trabajo aborda tanto el contenido como las restricciones que afectan a las ordenanzas municipales a la luz de la jurisprudencia judicial y administrativa. Para ello, se describirán los aspectos esenciales que distinguen a las ordenanzas municipales de otros cuerpos normativos, sus procedimientos de producción, el rol que cumplen las ordenanzas municipales en el sistema de fuentes del derecho administrativo y los límites que dichas regulaciones deben observar en virtud de nuestro ordenamiento jurídico. Una vez descrito el marco jurídico que regula las ordenanzas municipales, se analizarán los mecanismos de control jurídico o de legalidad sobre las ordenanzas municipales y se identificarán dos tipos de controles: uno preventivo y otro represivo, advirtiendo las deficiencias que se presentan en el control preventivo. Como corolario de lo señalado, se concluirá con una propuesta destinada a perfeccionar y reforzar el examen preventivo de legalidad de las ordenanzas municipales con el propósito de evitar, o al menos atenuar, el potencial efecto lesivo que dichos instrumentos normativos puedan provocar en los derechos fundamentales de las personas.
\end{abstract}

PALABRAS CLAVE Municipalidades, ordenanzas municipales, límites, control, legalidad.

ABSTRACT The present work addresses both the content and the restrictions to which the municipal ordinances are subject, in the light of judicial and administrative jurisprudence. To this end, the author develops the essential aspects that distinguish municipal ordinances from other regulatory bodies, their production procedures, the role of municipal ordinances in the system of sources of administrative law and the limits that these regulations must observe under of our legal system. Once described the legal framework that regulates municipal ordinances, the author analyzes the mechanisms of legal control or legality on municipal ordinances, identifying two types of controls: one preventive and one repressive, warning the deficiencies that are present in the preventive control. As a corollary to the foregoing, the author concludes with a proposal to improve and strengthen the preventive review of legality of municipal ordinances with the purpose of avoiding -or at least mitigating- the potential harmful effect that these normative instruments may cause in the fundamental rights of people. 
KEYWORDS Municipalities, municipal ordinances, limits, control, legality.

\section{Introducción}

Con el título de este trabajo aludimos al libro Justicia y seguridad jurídica en un mundo de leyes desbocadas del administrativista español Eduardo García de Enterría publicado en 1999. El objetivo es destacar que lo que el autor denunció hace algunas décadas atrás en relación con las leyes ocurre actualmente en Chile con respecto a las ordenanzas municipales.

En efecto, estamos inmersos en un mundo de ordenanzas municipales desbocadas, ya que son dictadas profusamente por las municipalidades en términos que muchas de ellas, incluso abordando materias propias de ley, exceden los límites que importan, como las funciones y atribuciones municipales, y nuestras libertades y derechos. A modo de ejemplo, pensemos en la ordenanza de la Municipalidad de Las Condes que prohíbe fumar en plazas y parques públicos; la ordenanza de la Municipalidad de Zapallar que prohíbe ir a la playa con mascotas; la ordenanza de la Municipalidad de Antofagasta que prohibía la vagancia y mendicidad en los bienes nacionales de uso público; la ordenanza de la Municipalidad de Recoleta que prohibía el rodeo; y en el proyecto de ordenanza de la Municipalidad de Quillota que prohibiría que menores de catorce años transiten por la calle después de la una de la madrugada sin la compañía de un adulto.

Esta «ordenancitis», que "amenaza con transformarnos en un Estado federal» ${ }^{1}$ se debe, por una parte, al hecho de que muchos alcaldes -y también concejales- han visto en las ordenanzas municipales una forma de hacer visible su gestión o "poner temas» a nivel nacional en beneficio de su carrera política. Por otra parte, se debe al hecho de que las ordenanzas municipales no están sometidas a un control de legalidad preventivo con la intensidad que exige el hecho de que puedan regular materias propias de ley, como el establecer limitaciones a derechos fundamentales (Constitución Política de la República de Chile, artículo 19, número 26), y la consecuente incidencia -y potencial lesividad- que ellas representan para nuestras libertades y derechos. Recordemos que las ordenanzas municipales no están sometidas al trámite de la toma de razón por parte de la Contraloría General de la República (Ley 18.695, 1988: artículo 53).

Por todo lo anterior es que actualmente es una necesidad estudiar los límites de las ordenanzas municipales y sus mecanismos de control, cuestión a la que nos abocaremos en este trabajo. Por lo pronto, sostenemos que si bien la jurisprudencia judicial y administrativa precisa con claridad los límites a los que deben atenerse las ordenanzas municipales, estos operan solo en forma represiva, a instancia de un particular que solicita pronunciamiento sobre su legalidad a la Contraloría General de la República o bien ejerce en su contra acciones judiciales (Chible Villadangos, 2014: 59-62). Debido a esto, es habitual que se aprueben ordenanzas municipales con disposiciones ilegales

1. Esta expresión fue empleada por el profesor Hernán Corral Talciani en un tweet emitido el 25 de octubre de 2018 en su cuenta personal. Está disponible en https://bit.ly/30GpjuN. 
y/o inconstitucionales y que, no obstante, rijan plenamente toda vez que se presumen conforme a derecho (Ley 19.880, 2003: artículo 3, inciso final), lo que en razón de lo señalado creemos que debe ser evitado a través de la introducción de mejoras al control de legalidad preventivo al que están sometidas.

\section{Las ordenanzas municipales}

Según el artículo 119 inciso 2 de la Constitución Política de la República de Chile, la ordenanzas municipales, manifestación de la potestad normativa de las municipalidades se definen conforme a la Ley Orgánica Constitucional de Municipalidades de 1988 como: ${ }^{2}$

Normas generales y obligatorias aplicables a la comunidad. En ellas podrán establecerse multas para los infractores, cuyo monto no excederá de cinco unidades tributarias mensuales, las que serán aplicadas por los juzgados de policía local correspondientes (Ley 18.695, 1988: artículo 12, inciso 2).

En cuanto a las materias que las ordenanzas municipales pueden regular, es posible distinguir aquellas cuya regulación es encomendada por la ley expresamente, ${ }^{3}$ y aquellas que están comprendidas dentro de las funciones y atribuciones que dicha ley otorga a las municipalidades en sus artículos 3, 4 y 5. En relación con lo anterior, del mismo modo es posible distinguir entre las ordenanzas de ejecución, que concretan el mandato general y abstracto de la ley en el ámbito local, y las autónomas, que no siendo de ejecución innovan en el ordenamiento jurídico (Sentencia del Tribunal Constitucional rol 1669-10, 2012: considerando 47).

En cuanto al procedimiento para la aprobación de ordenanzas municipales, es importante señalar que:

- Deben ser aprobadas por el alcalde con acuerdo del concejo (Ley 18.695, 1988: artículo 65, letra $\mathrm{k}$ ).

- No existe un deber general de aplicar en dicho procedimiento mecanismos de participación ciudadana (como la consulta, la audiencia pública, etcétera); pero parece muy conveniente en pos de obtener la mejor regulación. Por lo pronto, la respectiva ordenanza municipal de participación bien puede contemplar mecanismos al efecto (Ley 18.695, 1988: artículo 93).

2. Véase Bernaschina González (1952: 244-246); Boloña Kelly (2001: 20); Chible Villadangos (2014: 4754); Huidobro Salas (2010: 22-36); Pinilla Paredes (2016: 30-42); Román Cordero (2016: 16-19; 2017: 187191); Silva Cimma (1962: 283-285); Vergara Blanco (2017: 208-211).

3. Por ejemplo, la ordenanza de participación de la ciudadanía local (Ley 18.695, 1988: artículo 93); la ordenanza de plano regulador comunal (Ley 18.695, 1988: artículo 24, letra a); la ordenanza ambiental (Ley 18.695, 1988: artículo 25, letra f); la ordenanza sobre horarios de funcionamiento de los locales de expendio de alcohol (Ley 18.695, 1988: artículo 65, letra o); la ordenanza sobre cierre o medidas de control de calles o pasajes (Ley 18.695, 1988: artículo 65, letra q); y la ordenanza sobre la tenencia responsable de mascotas o animales de compañía en el territorio comunal (Ley 21.020, 2017: artículo 7). 
- No es necesario que ellas se contengan en un decreto alcaldicio. En todo caso, cuando así se procede (lo que es la regla general), tiene la virtud de explicitar en la parte considerativa de dicha resolución la motivación de la respectiva ordenanza municipal, lo que será de singular relevancia para su control de legalidad represivo.

- Deben ser publicadas «en los sistemas electrónicos o digitales que disponga la municipalidad» (Ley 18.695, 1988: artículo 12, inciso final; Sentencia de la Corte Suprema de Justicia rol 5379-2012, 2012). ${ }^{4}$

- Están exentas del trámite de toma de razón que corresponde a la Contraloría General de la República (Ley 18.695, 1988: artículo 53), lo cual es sin perjuicio del control que le corresponde a la unidad de control de la respectiva municipalidad (Ley 18.695, 1988: artículo 53).

\section{El rol de las ordenanzas municipales}

Históricamente, el rol de las ordenanzas municipales en el sistema de fuentes del derecho administrativo ha sido menor, pero en el último tiempo ha adquirido mayor relevancia, lo que se evidencia tanto en la práctica municipal como en la jurisprudencia del Tribunal Constitucional. En efecto, esta magistratura recientemente ha señalado que las ordenanzas municipales son manifestación de una potestad reglamentaria municipal, análoga a la potestad reglamentaria del presidente de la República, y que ellas concretan, especialmente si son de ejecución, el mandato general y abstracto de la ley en el plano local en tanto que el reglamento hace lo propio en el plano nacional.

Así, en la sentencia del Tribunal Constitucional, rol 1669-10, de 2012 se sostuvo que:

Tratándose de la potestad reglamentaria municipal, sin embargo, es necesario considerar que tiene que existir un espacio para los intereses municipales en la complementación o ejecución de la legislación. En ese sentido, la ley debe regular nacionalmente, pero con una uniformidad básica o esencial. El elemento normativo uniforme o común del legislador nacional debe ser, por lo mismo, no especialmente detallado. Por una parte, porque no puede no considerar las realidades diferentes de cada municipio. Las casi 350 municipalidades que existen en nuestro país, no son iguales. Tienen diferencias geográficas, de clima, de realidad económica, de densidad poblacional. Por la otra, porque el municipio cuenta con órganos representativos de los intereses comunes en su estructura organizativa (el Concejo Municipal, el alcalde). Ellos deben diseñar y aprobar las normas cuyos destinatarios son los habitantes de la comuna. Llevar la legislación a sus consecuencias prácticas, no puede prescindir de la realidad local (Sentencia del Tribunal Constitucional rol 1669-10, 2012: considerando 56).

4. Es importante destacar que esto está en correspondencia con lo preceptuado en el artículo 7 , letra c, de la Ley 20.285 de 2008. 
Por otra parte, en la sentencia del Tribunal Constitucional, rol 3063-16, de 2016 se planteó que:

Los preceptos censurados consagran la atribución municipal de dictar reglamentaciones ejecutorias de ley, generales y obligatorias, como resultan ser las ordenanzas municipales. Aquella potestad, se asemeja a la potestad reglamentaria de ejecución del presidente de la Republica, que establece el artículo 32, número 6, de la Constitución Política, en tanto importa el poder de desarrollar los mandatos legales, por medio de una regulación pormenorizada, para así conseguir su concreción (Sentencia del Tribunal Constitucional rol 3063-16, 2016: considerando 5).

\section{Los límites de las ordenanzas municipales}

Según el artículo $1^{\circ}$ de la Ley 18.575, las ordenanzas municipales, en tanto importan actuación formal de las municipalidades, órganos de la administración del Estado, deben sujetarse al principio de legalidad/juridicidad conforme a lo previsto en los artículos $6^{\circ}$ y $7^{\circ}$ de la Constitución Política de la República, y al artículo $2^{\circ}$ de la Ley Orgánica Constitucional de Bases Generales de la administración del Estado. En este sentido, el Tribunal Constitucional ha señalado que:

La potestad normativa del municipio está subordinada, por una parte, a la Constitución y a la ley. Ello significa que está sujeta a dichas normas y no puede contradecirlas o invadir su ámbito propio de regulación. Por la otra, está subordinada a las normas que dicte el presidente de la República en ejercicio de su potestad reglamentaria (Sentencia del Tribunal Constitucional, rol 1669-10, 2012: considerando 47).

Lo anterior se concreta en una serie de limitaciones que serán expuestas a continuación: ${ }^{5}$

Uno. Las ordenanzas municipales solo pueden regular materias comprendidas dentro de las funciones y atribuciones de las municipalidades, muy especialmente las que precisan los artículos 3, 4 y 5 de la Ley Orgánica Constitucional de Municipalidades. En este sentido, el Tribunal Constitucional señala que:

Las ordenanzas tienen un ámbito restringido de materias que pueden abordar. Estas dicen relación con las funciones que la Constitución y la ley les encargan a los municipios (artículo 118 de la Constitución y artículos 3 y 4 de la Ley Orgánica de Municipalidades). No obstante, cuando la Carta Fundamental le entrega la potestad normativa al Concejo Municipal, parece dar a entender que el único límite que tiene es de forma o de procedimiento, al señalar que la función normativa debe ejercerse «en la forma que determine la Ley Orgánica Constitucional respectiva» (artículo 119, inciso segundo). Pero dicho límite sustantivo emana de la propia naturaleza del municipio, cuya competencia es acotada a ciertos asuntos listados en la ley (Sentencia del Tribunal Constitucional rol 1669-10, 2012: considerando 49).

5. Para una sistematización anterior, véase Román Cordero (2016: 22; 2017: 193-194; 2019: 5-6) y Vergara Blanco (2017: 210-211). 
Así, por ejemplo, por muy correcto y necesario que sea establecer mayores y mejores normas de protección para los animales de los circos, las municipalidades no pueden hacerlo mediante ordenanzas municipales ni a través de ninguna otra clase de resolución municipal, ya que es un tema ajeno a sus funciones y atribuciones, pues antes corresponde a otros órganos de la administración, como el Servicio Agrícola y Ganadero. En este sentido, la Contraloría General de la República ha señalado que:

Es dable concluir que los municipios no están facultados para dictar una ordenanza que regule las condiciones de utilización de animales en los circos que se instalen en la respectiva comuna, así como tampoco agregar normas en tal sentido al ordenamiento local ya existente (Dictamen de la Contraloría General de la República 23.800, de 2015)

Dos. Las materias reguladas por las ordenanzas municipales no pueden estar comprendidas dentro de las competencias de otros órganos de la administración, especialmente si tienen atribuidas potestades normativas sectoriales. Con todo, si así fuera y esas materias están igualmente comprendidas dentro de las funciones y atribuciones de las municipalidades, lo que puede suscitarse muy especialmente con las denominadas funciones compartidas (Ley 18.695, 1988: artículo 4), las ordenanzas no pueden sino estar en correspondencia con el ejercicio que dicho órgano ha efectuado de sus competencias, en razón de los principios de legalidad/juridicidad y de coordinación (Ley 19.995, 2005: artículo 5, inciso 2).

Así, por ejemplo, muchas ordenanzas municipales que reglan a los establecimientos comerciales que explotan máquinas de destreza y dado que los juegos de destreza son todos aquellos que no son de azar, es decir, los que solo pueden ser explotados en casinos de juego (Ley 19.995, 2005: artículo 3, letra c), comienzan definiendo qué se entiende por juegos de azar en circunstancias que la Ley 19.995 ya los ha definido (Ley 19.995, 2005: artículo 3, letra a), y la potestad de interpretarla administrativamente corresponde a la superintendencia homónima (Ley 19.995, 2005: artículo 42, número 7). Asimismo, la potestad para confeccionar el denominado Catálogo de Juegos (Ley 19.995, 2005: artículo 3, letra b). Por tanto, a través de una ordenanza municipal ni de ninguna otra clase de resolución municipal las municipalidades no pueden definir los juegos de azar o interpretar su contenido y alcance, ya que lo contrario contravendría no solo el principio de legalidad/juridicidad, sino también el principio de coordinación (Dictamen de la Contraloría General de la República 7.368, de 2014), ya que impone a las municipalidades el deber de conformarse a la interpretación administrativa efectuada al respecto por la Superintendencia de Casinos de Juego (Pinilla Paredes, 2016: 114-122).

Tres. Las ordenanzas municipales no pueden otorgar a las municipalidades nuevas funciones o atribuciones, ya que esto corresponde exclusivamente a la ley. Así, por ejemplo, una ordenanza municipal no puede otorgar a una municipalidad como nueva función o atribución el imponer deberes a los padres con respecto a sus hijos escolares como, por ejemplo, el deber de enviarlos al colegio. En este sentido, la Contraloría General de la República ha señalado que «una ordenanza municipal no puede conferir 
funciones y atribuciones a un municipio como sucede en la especie, ya que el instrumento idóneo para ello, de acuerdo con el artículo 118 de la Constitución Política, es una ley orgánica constitucional» (Dictamen de la Contraloría General de la República 59.480, de 2011).

Cuatro. Las ordenanzas municipales no pueden traspasar a otros órganos de la administración o a particulares, las funciones y atribuciones que la ley ha otorgado a las municipalidades, más aún si estas son privativas (Ley 18.695, 1988: artículo 3) o esenciales (Ley 18.695, 1988: artículo 5). Así, por ejemplo, una ordenanza municipal no puede imponer a los vecinos el deber de mantener limpios los bienes nacionales de uso público aledaños a sus propiedades o regar los árboles o el césped que se hallen en ese espacio, ya que se encuentra comprendido dentro de la función esencial de las municipales de administración de los bienes nacionales de uso público existentes en la comuna (Ley 18.695, 1988: artículo 5, letra c). En este sentido, la Contraloría General de la República ha señalado que:

Es una función propia y esencial de estos (los municipios -nota nuestra-), lo que implica, por una parte, que no puede ser desarrollada con la participación de otros órganos de la administración del Estado y, por otra, que no puede ser traspasada a los vecinos de la comuna, correspondiéndole su cumplimiento de manera exclusiva y excluyente (Dictamen de la Contraloría General de la República 85.156, de 2013).

Cinco. Las ordenanzas municipales no pueden prohibir actividades que están permitidas por la ley. Conforme a este criterio, la Contraloría General de la República declaró la ilegalidad de una ordenanza que prohibió el rodeo, ya que:

No procede que mediante una ordenanza municipal se prohíba el ejercicio de una actividad deportiva reconocida por el ordenamiento jurídico, como acontece con el rodeo, ya que ello significaría una discriminación arbitraria y una contravención al principio de juridicidad (Dictamen de la Contraloría General de la República 10.191, de 2018)

Por otra parte, también declaró la ilegalidad de las ordenanzas municipales que prohibieron el uso de bolsas de plástico, ${ }^{6}$ ya que «no es posible que a través de una ordenanza se afecte, mediante una prohibición, el derecho a desarrollar una actividad económica, que asegura el artículo 19, número 21, de la Constitución Política» (Dictamen de la Contraloría General de la República 86.870, de 2014).

Asimismo, las ordenanzas municipales no pueden establecer más requisitos o restricciones para el desarrollo de actividades económicas que las impuestas por la Constitución Política de la República y las leyes (Constitución Política de la República de Chile, 1980: artículo 19, número 26). Conforme a este criterio, la Contraloría General de la República declaró la ilegalidad de las ordenanzas que, a propósito de

6. Con anterioridad a la Ley 21.10o de 2018, que prohíbe la entrega de bolsas de plástico de comercio en todo el territorio nacional. 
los locales comerciales que explotan máquinas de destreza, les estableció distancias mínimas con respecto a los establecimientos educacionales y especiales condiciones en cuanto a baños, aireación y aislamientos de ruido, ya que en cuanto a lo primero las ordenanzas:

En ningún caso pueden establecer mayores requisitos o restricciones para el desarrollo de las actividades económicas, que aquellas que han sido impuestas por la Constitución Política y las leyes. [...] La fijación de distanciamientos mínimos a los locales comerciales de que se trata en relación con otro tipo de establecimientos, importa una restricción especial al desarrollo de una actividad económica que vulnera tanto la garantía constitucional antes referida (Constitución Política de la República de Chile, 1980: artículo 19, número 21 -nota nuestra-). (Dictamen de la Contraloría General de la República 45.262, de 2013).

Además, en cuanto a lo segundo:

No corresponde que mediante este tipo de cuerpos normativos se regulen materias propias de la Ley General de Urbanismo y Construcciones o de su ordenanza u otros cuerpos normativos, y se remitan o reproduzcan sus disposiciones, apartándose, por lo demás, en algunos aspectos de aquellas (Dictamen de la Contraloría General de la República 43.033, de 2016).?

Seis. Las ordenanzas municipales no pueden ser arbitrarias, vale decir, no deben obedecer al mero capricho. Al respecto, cabe señalar que en el control de legalidad represivo el órgano a cargo (tribunales o Contraloría General de la República) analizará al efecto muy especialmente la parte considerativa del decreto alcaldicio en el que se contenga la ordenanza municipal (y si esta no se contiene en la resolución, ya que ello no es necesario, las razones que se tuvieron en consideración para su aprobación por el concejo, a la luz de las actas de la respectiva sesión), a fin de determinar si ella está o no debida y correctamente motivada. Por ejemplo, con respecto a la ordenanza de la Municipalidad de Antofagasta que prohibió la vagancia y mendicidad en bienes nacionales de uso público, la Corte de Apelaciones de Antofagasta, en un acto de rechazo del recurso de protección deducido en su contra, sostuvo que:

La motivación de la ordenanza viene dada en su parte considerativa de la que se extrae que busca velar por la circulación expedita de vehículos en la vía pública, el resguardo de los espacios y bienes nacionales de uso público y salvaguardar la seguridad púbica comunal, por lo que no existe una desviación del fin público, además, de contar con la debida motivación -problemática social- que pretende solucionarse con la ordenanza, por lo que no puede entenderse que esta sea antojadiza o caprichosa (Sentencia de la Corte de Apelaciones de Antofagasta rol 2.988-2017, 2017: considerando undécimo).

7. A su vez, confirma el Dictamen de la Contraloría General de la República 34.267, de 2015. 
Asimismo, si las ordenanzas municipales establecen discriminaciones, en ningún caso pueden ser arbitrarias (Constitución Política de la República de Chile, 1980: artículos 19, número 2 y 21; Ley 20.609, 2012: artículo 1, inciso 2). Así, por ejemplo, en el caso antes referido de la ordenanza municipal que, a propósito de los locales comerciales que explotan máquinas de destreza les estableció distancias mínimas con respecto a establecimientos educacionales, la Contraloría General de la República sostuvo que contravenía la garantía «consagrada en el artículo 19, número 2, de la Ley Suprema, en cuanto asegura el derecho a que ni la ley ni autoridad alguna podrán establecer diferencias arbitrarias» (Dictamen de la Contraloría General de la República 45.262, de 2013).

Siete. En relación con las restricciones o limitaciones establecidas por ley y especificadas a través de un decreto (ya sea reglamentario o no), a nivel nacional, las ordenanzas municipales no pueden establecer estándares más estrictos a nivel local. Así, por ejemplo, una ordenanza municipal sobre ruidos no puede establecer niveles de emisión permitidos más estrictos que los fijados por el presidente de la República mediante el respectivo decreto. En este sentido, la Contraloría General de la República señala que:

Una ordenanza municipal no puede contravenir lo establecido en la respectiva norma de emisión. De este modo, no corresponde que en virtud de lo dispuesto en la ordenanza municipal en examen, una persona pueda ser sancionada a pesar de dar cumplimiento a los parámetros fijados por el aludido decreto número 38, de 2011 (Dictamen de la Contraloría General de la República 26.650, de 2016)

Ocho. Las ordenanzas municipales no pueden incurrir en el vicio de la desviación de fin o de poder. Así, por ejemplo, en el caso de que una municipalidad que modifica su ordenanza municipal de cobro de derechos, estableciendo el pago de derechos excesivos con respecto a un nuevo servicio (publicidad con pantallas LED en edificios privados); servicio respecto del cual tiempo atrás un particular le solicitó los permisos correspondientes y esta nada resolvió, razón por la cual este reclamó ante la Secretaría Regional Ministerial de Vivienda y Urbanismo, la que finalmente ordenó a la municipalidad otorgarlos. Es dable suponer que dicha modificación tuvo por finalidad el dificultar o impedir que este particular lleve a cabo este nuevo servicio, es decir, se generó una desviación de fin o de poder. En efecto, la Corte Suprema sostuvo que:

Las circunstancias bajo las cuales se procedió a la modificación de la ordenanza y las expuestas en el mismo acto administrativo, permiten razonablemente presumir que el fin que tuvo a la vista la autoridad fue otro, que se vincula con la situación particular que afecta a la recurrente y a las acciones que esta debió ejercer para lograr una respuesta de la administración (Sentencia de la Corte Suprema rol 55.119-2016, 2016: considerando décimo primero).

Nueve. Las ordenanzas municipales no pueden establecer sanciones distintas a la multa de hasta cinco unidades tributarias mensuales como, por ejemplo, la clausura, el comiso, la revocación -de actos favorables-, etcétera (Dictamen de la Contraloría General de la República 54.966, de 2013), y tampoco pueden disponer que dicha san- 
ción de multa sea adjudicada por un órgano distinto del respectivo juez de policía local como, por ejemplo, directamente por la misma municipalidad.

Diez. Las ordenanzas municipales solo pueden versar sobre materias de administración y en caso alguno sobre materias de gobierno. Esto no es sino lógica consecuencia del hecho de que las municipalidades solo son órganos de administración, y no de gobierno. ${ }^{8}$ Así, por ejemplo, si como alguna doctrina plantea, la migración se entendiera como una materia propia de gobierno, en ningún caso podría ser tratada por una ordenanza municipal.

Once. Las ordenanzas municipales, especialmente si son de ejecución, deben conformarse a la ley y al reglamento, y en ningún caso pueden invadir el ámbito nacional, que es propio de este último. Viceversa, el reglamento no puede invadir el ámbito local, que es propio de las ordenanzas municipales, lo que deberá ser controlado por la Contraloría General de la República al momento de efectuar la toma de razón del mismo. En este sentido, la sentencia del Tribunal Constitucional rol 3.489, sobre control preventivo de constitucionalidad de la actual Ley 21.020 sobre Tenencia Responsable de Mascotas y Animales de Compañía (coloquialmente conocida como «Ley Cholito»), contiene la prevención de los ministros señor Aróstica, señora Brahm y señor Letelier, que a propósito de la relación reglamento-ordenanza, señaló que:

Corresponderá a la Contraloría General de la República, en el trámite de toma de razón, verificar que este reglamento presidencial solamente cubra aspectos básicos a nivel nacional, dejando suficiente espacio para que en este orden de asuntos pueda tener lugar la potestad normativa municipal (Sentencia del Tribunal Constitucional rol 3489-17, 2017: prevención de los ministros señor Aróstica, señora Brahm y señor Letelier, considerando 4)

Doce. Las ordenanzas municipales no pueden desnaturalizar instituciones propias del derecho administrativo y municipal. Esto acontecería si una ordenanza municipal establece que los permisos municipales de ocupación de bien nacional de uso público solo pueden ser revocados como consecuencia del incumplimiento de sus deberes por parte del permisionario, en circunstancias que la Ley Orgánica Constitucional de $\mathrm{Mu}$ -

8. Conforme a la Constitución, las municipalidades son corporaciones autónomas de derecho público con personalidad jurídica y patrimonio propio, que tienen a su cargo, conforme precisa el título del penúltimo parágrafo de su título XIV, la «administración comunal», y no el «gobierno comunal» (o, si se quiere, el «gobierno local»). En efecto, en correspondencia con ello, véase la Constitución Política de la República de Chile (1980: artículo 118, inciso 1), así como la Ley 18.695 (1988: artículo 1). Esta precisa que «la administración local de cada comuna o agrupación de comunas que determine la ley reside en una municipalidad». Esto queda aún más en evidencia si se considera que el capítulo en el que son tratadas (XIV) se intitula «Gobierno y administración interior del Estado»; que, a su vez, los títulos de los parágrafos que, dentro de dicho capítulo, anteceden a aquel que las trata, son: «Gobierno y administración regional» y «Gobierno y administración provincial»; y que en la Constitución Política de la República de Chile (1980: artículo 126 bis), último artículo de ese capítulo, se refiere expresamente al gobierno y administración de los territorios especiales. 
nicipalidades otorga al efecto una amplia potestad discrecional al alcalde (Ley 18.695, 1988: artículo 63, letra g) y los caracteriza como esencialmente precarios (Ley 18.695, 1988: artículo 36) (Sentencia de la Corte Suprema Rol 3.605-2008, 2010). Por otra parte, también acontecería si una ordenanza municipal facultara a una municipalidad para autorizar el cierre de los bienes nacionales de uso público en hipótesis distintas a las contempladas por la Ley Orgánica Constitucional de Municipalidades (Ley 18.695, 1988: artículos 5, letra c; y 65, letra q), ${ }^{9}$ privándolos así de las características esenciales de su uso, es decir, la igualdad, la libertad y la gratuidad (Sentencias del Tribunal Constitucional roles 1281-08, 2009 y 1669-10, 2012). Así, en relación con el primer ejemplo, la Corte Suprema sostiene que:

La municipalidad escogió la figura jurídica del permiso [...] y no obstante ello en los artículos 20 y 26 (de la ordenanza -nota nuestra-) estableció que este se puede dejar sin efecto únicamente por incumplimiento de las obligaciones de la empresa respectiva, lo que resulta incongruente con su naturaleza precaria (Sentencia de la Corte Suprema rol 3.605-2008, 2010: considerando decimocuarto)

\section{El actual control de las ordenanzas municipales: análisis y propuestas}

Sobre los controles que afectan a las ordenanzas municipales, es posible señalar que en cuanto al control de legalidad preventivo las ordenanzas municipales están exentas del trámite de toma de razón ante la Contraloría General de la República por expresa disposición legal (Ley 18.695, 1988: artículo 53). ${ }^{10}$ Esto es sin perjuicio del control que le corresponde realizar a la unidad de control municipal. Nos parece muy limitado tanto por la oportunidad en la que tiene lugar (Ley 18.695, 1988: artículo 29, letra c), ${ }^{11}$ así como por la escasa independencia y fortaleza de aquella unidad frente al alcalde y concejo (Ley 18.695, 1988: artículo 29 inciso final), ${ }^{12}$ máxime cuando en no pocas oportunidades es particularmente patente en estos últimos su voluntarismo en pos de la aprobación de ciertas ordenanzas.

Lo anterior no impide que el alcalde, en tanto autoridad máxima de la municipalidad (Ley 18.695, 1988: artículo 56), pueda requerir, en el marco del proceso de creación de una ordenanza municipal, pronunciamiento a la Contraloría General de la República conforme a las normas generales y a la práctica administrativa (Dictamen de la Contraloría General de la República 24.143, de 2015; Ley 10.336, 1952: artículos 6 y 9),

9. Me refiero a la facultad de las municipalidades para autorizar el cierre de calles y pasajes con una sola vía de acceso y salida durante cinco años por razones de seguridad.

10. En efecto, este artículo dispone que «las resoluciones que dicten las municipalidades estarán exentas del trámite de toma de razón, pero deberán registrarse en la Contraloría General de la República cuando afecten a funcionarios municipales».

11. La representación que puede efectuar esta unidad tiene lugar «dentro de los diez días siguientes a aquel en que la unidad de control haya tomado conocimiento de los actos».

12. Resguardado por un específico procedimiento de remoción del jefe de la unidad de control, conforme a lo previsto en el artículo citado. 
sobre la legalidad de su texto antes de su publicación, ya sea antes o después de su aprobación por el concejo municipal.

Sobre el control de legalidad represivo se establece que se puede encauzar:

- A través de la vía jurisdiccional mediante el ejercicio de acciones como el reclamo de ilegalidad municipal (Ley 18.695, 1988: artículo 151), la nulidad de derecho público (Constitución Política de la República de Chile, 1980: artículos 6 y 7), el recurso de protección (Constitución Política de la República de Chile, 1980: artículo 20), el amparo económico (Ley 18.971, 1990), y la acción de no discriminación arbitraria (Ley 20.609, 2012: título II).

- A través de la vía administrativa; por ejemplo, requiriendo pronunciamiento al contralor general de la República sobre la legalidad de las mismas, siempre que no sea un asunto litigioso en los términos que establece la Ley 10.336 en su artículo 6.

En consecuencia, dado que en la actualidad las ordenanzas municipales son potencialmente lesivas de derechos fundamentales y que el control de legalidad preventivo al que están sujetas no tiene la intensidad que precisa en atención a esto, creo que debe ser reforzado. Así, proponemos que en lo inmediato se promueva que los alcaldes efectúen consultas a la Contraloría General de la República sobre la legalidad de los textos de sus ordenanzas antes de ser publicadas, ya sea antes o después de su aprobación por el Concejo Municipal. ${ }^{13}$ Esta práctica incluso puede ser formalizada a través de convenios de colaboración interorgánica entre municipalidades y la Contraloría General de la República. Por otra parte, en lo inmediato proponemos que las ordenanzas municipales queden sometidas al trámite de toma de razón, y dado que la exclusión de dicho trámite ha sido establecida por disposición legal expresa contenida en la Ley Orgánica Constitucional de Municipalidades, es preciso es que esta se modifique en este sentido como ha acontecido recientemente con el reglamento interno que fija la planta del personal municipal, a través de la Ley 20.922 de 2016 y la Ley 18.695 de 1988 en su artículo 49 bis. ${ }^{14}$ En este contexto, el legislador podría optar por someter a ese trámite a todas las ordenanzas o bien solo a las referidas a determinadas materias que precise, y especialmente cuando digan relación con derechos fundamentales.

\footnotetext{
13. «La Florida será la primera comuna que impedirá reglamentos de edificios que prohíban tener mascotas», EMOL, 25 de octubre de 2018, disponible en https://bit.ly/2XRtmYj.

14. En efecto, conforme al artículo citado: «Artículo 49 bis. Los alcaldes, a través de un reglamento municipal, podrán fijar o modificar las plantas del personal de las municipalidades, estableciendo el número de cargos para cada planta y fijar sus grados, de conformidad al título II del decreto ley 3.551, del Ministerio de Hacienda, promulgado el año 1980 y publicado el año 1981. Sin perjuicio de lo dispuesto en el artículo 53, el reglamento que se dicte ejerciendo la potestad reconocida en el inciso anterior estará sometido al trámite de toma de razón ante la Contraloría General de la República y se publicará en el Diario Oficial.»
} 


\section{Conclusión}

A modo de conclusión, puedo señalar que a la luz de la práctica municipal y la jurisprudencia del Tribunal Constitucional, en el último tiempo se ha revalorizado el rol de las ordenanzas municipales en el sistema de fuentes del derecho administrativo. En efecto, dicha magistratura ha señalado que la potestad en cuya virtud son dictadas las ordenanzas constituye una «potestad reglamentaria municipal» (Sentencia del Tribunal Constitucional rol 1669-10, 2012: considerando 56), que «se asemeja a la potestad reglamentaria de ejecución del presidente de la Republica, que establece el artículo 32, número 6, de la Constitución Política» (Sentencia del Tribunal Constitucional rol 309316, 2016: considerando 5).

De esto se desprende que, como lo acredita la práctica, actualmente las ordenanzas municipales son potencialmente lesivas de derechos fundamentales, lo que exige reforzar el control de legalidad preventivo al que están sometidas.

Para esto proponemos que en lo inmediato se promueva el hecho de que los alcaldes efectúen consultas a la Contraloría General de la República sobre la legalidad de los textos de sus ordenanzas antes de ser publicadas, ya sea antes o después de su aprobación por el Concejo Municipal, una práctica que incluso puede ser formalizada en convenios de colaboración interorgánica entre municipalidades y la Contraloría General de la República. Por otra parte, en lo mediato proponemos que a través de la modificación de la Ley Orgánica Constitucional de Municipalidades, las ordenanzas queden sujetas al trámite de la toma de razón. En este contexto, el legislador podría optar por someter a ese trámite a todas las ordenanzas o solo a las referidas a determinadas materias que precise, y especialmente cuando estas tengan relación con derechos fundamentales.

\section{Referencias}

Bernaschina González, Mario (1952). Derecho municipal chileno. Tomo I. Santiago: Jurídica de Chile.

Boloña Kelly, Germán (2001). Derecho municipal chileno. Santiago: Jurídica Conosur. Chible Villadangos, María José (2014). La idoneidad de las ordenanzas municipales para satisfacer las necesidades públicas y las exigencias ciudadanas. Memoria de prueba para optar al grado de licenciado en Ciencias Jurídicas y Sociales. Santiago: Facultad de Derecho Universidad de Chile.

García de Entrerría, Eduardo (1999). Justicia y seguridad jurídica en un mundo de leyes desbocadas. Madrid: Civitas.

Huidobro Salas, Ramón (2010). Tratado de derecho administrativo. Derecho y administración comunal. Santiago: Legal Publishing.

Pinilla Paredes, Francisca (2016). Las municipalidades y los juegos de azar. Memoria de prueba para optar al grado de licenciado en Ciencias Jurídicas y Sociales. Santiago: Facultad de Derecho Universidad de Chile. 
Román Cordero, Cristian (2016). «Ordenanzas municipales y tenencia responsable de mascotas». Revista Derecho y Humanidades, 27: 13-36. DOI: 10.5354/0719-2517.2016.46053.

-. (2017). «ORDENANZAS MUNiCipales: LímiteS y CONTROL», en Asociación Chilena de Derecho Constitucional (compilador), Teoría politica y constitucional. Libro en homenaje al profesor Ismael Bustos Concha (pp. 183-201). Santiago: Jurídica de Chile.

-. (2019). "El "DeCÁlogo" de las ordenanzas municipales». ReVista JuRídica MUNICIPAL, 3: 5-6. Disponible en https://bit.ly/2M7kOp6.

Silva Cimma, Enrique (1962). Tratado de derecho administrativo chileno y comparado. Introducción y fuentes. Tomo I. 2. ${ }^{\mathrm{a}}$ ed. Santiago: Jurídica de Chile.

Vergara Blanco, Alejandro (2017). «Ordenanzas municipales: límites, legitimidad democrática, problemas y propuestas. Estudio de caso: aguas, bienes de uso público y sanciones». En Propuestas para Chile (pp. 203-242). Santiago: Pontificia Universidad Católica.

\section{Sobre el autor}

Cristian Román Cordero es abogado y licenciado en Ciencias Jurídicas y Sociales de la Universidad de Chile. Es profesor de Derecho Administrativo de la Facultad de Derecho de la Universidad de Chile. 